TẠP CHÍ KHOA HỌC ĐÄI HỌC TÂN TRÀO
ISSN: 2354 - 1431
http://tckh.daihoctantrao.edu.vn/

\title{
TRI THỨC DÂN GIAN TRONG LAO ĐỘNG SẢN XUẤT ĐƯợC PHẢN ÁNH QUA TỤC NGŨ̉ TÀY
}

\author{
Hà Thị Chuyên ${ }^{1 *}$ \\ ${ }^{1}$ Đại học Tân Trào \\ *Email: hoahoctro8387@gmail.com
}

\section{Thông tin bài viết}

Ngày nhận bài:

$15 / 7 / 2020$

Ngày duyệt đăng:

20/9/2020

Từ khóa:

tri thức, dân gian, lao

động, sản xuất, tục ngũ Tày

\section{Tóm tắt}

Khảo sát tri thức dân gian nhằm giới thiệu, bảo tồn, phát huy những kinh nghiệm quý báu của đồng bào dân tộc Tày đang là một nhu cầu cấp bách. Bởi ngôn ngữ và văn hóa của các dân tộc thiểu số nói chung và dân tộc Tày nói riêng đang đứng trước nguy cơ mang tính toàn cầu đó sự mai một và tiêu vong. Khảo sát tri thức dân gian về lao động, sản xuất trong tục ngữ Tày thông qua các ấn phẩm đã được xuất bản cho thấy đồng bào thường quan tâm đến những kinh nghiệm về dự báo thời tiết, mùa vụ, trồng trọt, chăn nuôi,... Những tri thức dân gian này cần được lựa chọn để truyền dạy cho con em đồng bào dân tộc Tày nói riêng và cộng đồng nói chung.

\section{Mở đầu}

Tri thức dân gian (hay tri thức bản địa, tri thức địa phương) được hiểu theo nghĩa rộng là: các truyền thống lâu đời, kinh nghiệm, thực tiễn sống của một cộng đồng liên quan đến môi trường tự nhiên, xã hội, đời sống, tư duy của cộng đồng đó. Tri thức dân gian được truyền từ thế hệ này qua thế hệ khác, người này qua người khác, thông qua truyện kể, huyền thoại, văn học dân gian, các nghi lễ, lễ thức, tập quán, lề thói, quy định, luật tục. Đồng bào dân tộc Tày vốn là những cư dân nông nghiệp. Do vậy, để có một vụ mùa được thu hoạch, họ phải bỏ ra rất nhiều thời gian và công sức. Khi khoa học và các phương tiện thông tin đại chúng chưa phát triển, đồng bào chủ yếu dựa vào việc quan sát sự biến chuyển của vạn vật, từ năm này qua năm khác, sđời này qua đời khác để phát hiện ra các quy luật tự nhiên. Những quy luật ấy được đồng bào tích lũy thành vốn tri thức dân gian.

Để có cơ sở về mặt định lượng cho việc nghiên cứu chúng tôi tiến hành khảo sát 2251 câu tục ngữ chúng tôi thấy rằng đồng bào dành sự quan tâm nhiều đến các phương diện như: thời tiết, mùa vụ, trồng trọt, chăn nuôi, buôn bán...

\section{Nội dung}

\subsection{Thòi tiết}

Nông nghiệp của người Tày trước kia phụ thuộc hoàn toàn vào tự nhiên. Vì vậy, thời tiết có ý nghĩa hết sức quan trọng và là mối quan tâm hàng đầu của đồng bào. Trước mỗi vụ trồng trọt, đồng bào thường quan sát môi trường xung quanh để đưa ra những dự báo thời tiết góp phần tạo nên những mùa vụ bội thu. Khảo sát các căn cứ đưa ra dự báo thời tiết được đồng bào dân tộc Tày sử dụng trong tục ngữ chúng tôi thu được kết quả sau: 
Bảng 1 Căn cứ đưa ra các dự báo thời tiết

\begin{tabular}{|c|c|c|c|}
\hline STT & \multicolumn{2}{|c|}{ Căn cứ dụ̣ báo } & Tần số \\
\hline 1. & \multirow{6}{*}{ Thiên tượng } & sấm & 33 \\
\hline 2. & & trời & 11 \\
\hline 3. & & mây & 10 \\
\hline 4. & & sao & 5 \\
\hline 5. & & gió & 3 \\
\hline 6. & & cầu vồng & 1 \\
\hline 7. & \multirow{14}{*}{ Vật tượng } & hoãng & 4 \\
\hline 8. & & diều hâu & 3 \\
\hline 9. & & cuốc & 3 \\
\hline 10. & & cóc & 2 \\
\hline 11. & & ếch & 2 \\
\hline 12. & & hươu & 2 \\
\hline 13. & & nai & 2 \\
\hline 14. & & ong & 2 \\
\hline 15. & & nhái & 1 \\
\hline 16. & & trâu & 1 \\
\hline 17. & & kiến & 1 \\
\hline 18. & & quang quýnh & 1 \\
\hline 19. & & cá & 1 \\
\hline 20. & & con thiêu thân & 1 \\
\hline 21. & & cây gạo & 2 \\
\hline 22. & & mắc mặt & 1 \\
\hline 23. & Thực vạt & mác foòng & 1 \\
\hline 24. & & cây lai & 1 \\
\hline 25. & \multirow{3}{*}{ Căn cứ khác } & lửa & 4 \\
\hline 26. & & vòng sắt & 2 \\
\hline 27. & & vòng đồng & 2 \\
\hline \multicolumn{3}{|c|}{ Tổng } & 102 \\
\hline
\end{tabular}

Qua bảng 1 , chúng tôi thấy rằng, đồng bào dân tộc Tày căn cứ vào rất nhiều phương diện khác nhau để đưa các dự báo về thời tiết. Trong đó, thiên tượng là phương diện thường được đồng bào căn cứ để đưa các dự báo. Trong các hiện tượng tự nhiên sấm là yếu tố được đồng bào sử dụng nhiều nhất 33/ 102 lượt dùng. Người Tày sử dụng tiếng sấm để dự báo thời thời tiết bởi đồng bào quan niệm sấm là trống của trời. Bằng 
kinh nghiệm của mình đồng bào dân tộc Tày đã đúc rút được: fạ đăng cón bấu luổn phân (trời sấm trước không hay mưa) [3, tr. 139]. Sấm trước khi mưa thì lượng mưa nhỏ, thời gian mưa ngắn, cục bộ, đôi khi là bên này đường thì mưa mà bên kia đường thì nắng. Hiện tượng này được khoa học giải thích là do khu vực đó chịu nhiệt nóng không đồng đều hình thành. Ngược lại, nếu mưa rồi mới có sấm chớp thì trận mưa đó sẽ to do nhiệt độ thấp sự ngưng tụ cao. Thời điểm xuất hiện tiếng sấm cũng là cơ sở để đồng bào Tày dự báo thời tiết $F a$ đăng buơn chiêng phiêng lắt lý/ $F a$ đăng buơn nhi chí thau mằn/ Fạ đăng buon slam ham dủng doảng (Trời sấm tháng giêng nước tràn ngập/ Trời sấm tháng hai gỡ dây lang/ Trời sấm tháng ba khiêng đàng hoàng, không vội vã) [3, tr. 138]

Ngoài căn cứ vào tiếng sấm để dự báo thời tiết người Tày còn quan sát các đám mây, màu sắc của mây, sự lưu chuyển của đám mây trên bầu trời, ánh sáng mặt trời, mặt trăng, các vì sao, hương vị của gió trong không khí để có thể đoán biết được diễn biến thời tiết.

Fạ kết pja lẻ phân/ Fạ kết hên lẻ đét (Trời có mây hình vẩy cá thì mưa/ Trời có mây hình vẩy beo thì nắng) [3, tr.139]

Ngoài việc quan sát mây để đưa ra các dự báo về thời tiết thì đồng bào dân tộc Tày còn căn cứ vào gió.

- Lồm buơong băc lẻ phân/ Lồm bương đông lẻ đet. (Gió hướng bắc thì mưa/ Gió hướng đông thì nắng.) [3, tr. 153]
- Lồm pảo cón bấu phân/ Lai đao bân fạ đét (Gió thổi trước không mưa / Đêm nhiều sao ngày nắng.) [3. Tr. 153]

Ngoài căn cứ vào thiên tượng, đồng bào dân tộc Tày còn căn cứ vào vật tượng để đưa ra các dự báo về thời tiết. Trong các vật tượng dùng để dự báo thời tiết đồng bào dân tộc Tày sử dụng động vật nhiều hơn thực vật. Các loài động vật hoang dã như: hoẵng, hươu, diều hâu, cuốc, ếch... chiếm ưu thế tuyệt đối so với các loài vật nuôi gia đình.

Trong các vật tượng dùng để dự báo thời tiết hoẵng có tần số cao hơn cả.

- Nạn khóc vạ đét/ Quang keéc va phân (Hoãng kêu trời nắng/ Hươu kêu trời mưa) [3, tr. 158]

- Nạn khuô vạ đét/ Quang ket fạ phân (Hoãng cười trời nắng/ Hươu giác trời mưa) [3, tr. 158]

Ngoài quan sát các loài thú trên rừng thì đồng bào dân tộc Tày còn quan sát sự vật động của những loài vật gần gũi với sinh hoạt như: ếch, nhái, chim...

- Cốp khuyết loỏn fạ phân/ Lăm quạ bân fạ đét (Ếch nhái kêu trời mưa/ Diều hâu lượn cao trời nắng) [3, tr. 135]

- Mèng mẩu khẩu dắp đén nhao nhao / Bấu lồm tố phân bấu quá đai (Thiêu thân thi nhau lao vào đèn/ Không gió cũng mưa chắc chắn.) [ $3, \operatorname{tr} 155]$

Thời tiết không chỉ được đồng bào dân tộc Tày dự đoán thông qua quan sát các hiện tượng xung quanh mà đồng bào còn quan tâm đến các hiện tượng. Qua khảo sát các phương diện dự báo thời tiết trong tục ngữ dân tộc Tày chúng tôi thu được kết quả sau:

Bảng 2. Các hiện tượng thời tiết được đồng bào dụ̣ báo qua tục ngữ

\begin{tabular}{|c|l|r|r|l|c|}
\hline $\begin{array}{c}\text { ST } \\
\mathbf{T}\end{array}$ & Các hiện tượng & Tần số & STT & Các hiện tượng & Tần số \\
\hline 1 & Mưa & 29 & 6 & Được mùa & 5 \\
\hline 2 & Lũ lụt & 14 & 7 & Mất mùa & 4 \\
\hline 3 & Nắng & 13 & 8 & Nóng & 2 \\
\hline 4 & Rét & 12 & 9 & Gió to & 2 \\
\hline 5 & Hạn hán & 11 & & Tổng & 92 \\
\hline
\end{tabular}

Qua bảng 2, chúng tôi thấy rằng, trong tục ngữ Tày, hiện tượng mưa được đồng bào đề cập đến nhiều nhất, sau đó là lũ lụt. Điều này có lẽ xuất phát từ thực tế sản xuất, bởi người Tày vốn là những cư dân nông nghiệp. Mà trong hoạt động sản xuất nông nghiệp nước là yếu tố hàng đầu ảnh hưởng tới quá trình sản xuất.
Qua khảo sát chúng tôi thấy rằng số lượng các câu tục ngữ phản ánh hiện tượng thời tiết rét có tần số sử dụng không nhỏ. Những câu tục ngữ phản ánh hiện tượng thời tiết rét góp phần phản ánh đặc điểm cư trú của người Tày. Họ sống chủ yếu ở trung du và miền núi phía Bắc nước ta. Nơi có hai kiểu thời tiết phân 
hóa rõ rệt là nóng và rét. Điều này làm nên đặc trưng riêng biệt cho tục ngữ của họ. Một nét riêng biệt nữa về thời tiết được phản ánh trong tục ngữ Tày đó là các tri thức về thời tiết biển hoàn toàn không được phản ánh. Điều này có thể được lí giải do không gian sinh sống của người Tày xa biển.

\subsection{Mùa vụ}

Sống hòa mình với thiên nhiên, các hiện tượng gần gũi như: quả chín, hoa nở, mùa lá...đã trở thành dấu hiệu để người Tày nhận biết thời điểm canh tác.

Đồng bào dân tộc Tày cư trú ở miền núi phía Bắc nước ta, nơi có diện tích rừng khá lớn. Do vậy, đồng bào thường căn cứ vào dấu hiệu mùa quả chín để dự báo nông vụ: “Mác lót rường hang, muơng phai lèo chuoóng" (quả nhót đỏ trôn, mương phai lo sửa). Quả nhót thường chín vào cuối tháng 2 âm lịch. Đây là thời điểm vùng núi phía Bắc nước ta bước sang mùa xuân khí hậu dần ấp áp. Do vậy, đồng bào cần chuẩn bị cho một vụ mùa mới. Ngoài dựa vào mùa quả nhót chín thì để dự báo mùa vụ người Tày còn dựa vào một số loại quả đặc trưng của vùng như: Mác phầy ốt rù đăng ván chả, mác phầy cắm hăm mạ đăm nă" (quả dâu da vừa lỗ mũi gieo mạ, dâu da tím dái ngựa cấy lúa). Dâu da chín bắt đầu từ tháng 3 tới hết tháng 5 âm lịch. Thời điểm này thời tiết nóng và mưa nhiều, ngày dài (nhiều ánh sáng), rất thuận lợi cho việc làm đất. Đồng bào dân tộc Tày thường gieo mạ vào tháng 3 , nhưng cũng có năm thời tiết thất thường, tháng 3 vẫn rét chưa gieo mạ được. Do vậy, để có thể xác định chính xác thời gian gieo mạ đồng bào dân tộc Tày thường quan sát kích thước quả dâu da, vì quả dâu da đủ nhiệt độ, độ ẩm, ánh sáng thì nó mới phát triển.

Đồng bào dân tộc Tày không chỉ căn cứ vào mùa quả chín để xác định nông lịch mà còn căn cứ vào những loại cây đặc trưng cho vùng trung du và miền núi phía Bắc: Bâu xâu kheo/ Noọng slao dá lỉn (Lá xau xau xanh/ Con gái chớ đi chơi) [3, tr. 188]. Cây xau xau là loại cây thân gỗ, thường mọc trên rừng. Khi mùa xuân sang, cây nẩy lộc, đâm chồi rất mạnh. Ngoài căn cứ vào xau xau thì đồng bào dân tộc Tày còn căn cứ vào một số loài hoa đặc trưng: Bjoóc cháu tốc tỉ / Khẩu tẩy slia tôm (Hoa chẩu rơi / Ngô vãi đất) [3, tr 189]. Cứ vào độ tháng 3 tháng 4 , hoa chẩu lại bung nở với vô vàn những bông trắng muốt, tinh khôi. Nó làm bừng sáng cả núi rừng và đó cũng là dấu hiệu để đồng bào dân tộc Tày bắt đầu một mùa tra ngô.

Để xác định nông vụ ngoài căn cứ vào những dấu hiệu như: quả chín, hoa nở, mùa lá... đồng bào dân tộc Tày còn căn cứ các tiết khí trong nông lịch: Đăm nà quá hạ chí/Sli tháp ngám đảy gòn (Cấy lúa sau hạ chí/muời gánh mói được một dậu). Tiết Hạ chí vào tháng 5 âm lịch là thời điểm giữa của mùa hạ. Bán cầu Bắc vào thời gian tiết hạ chí sẽ ngả về phía mặt trời nhiều hơn so với bán cầu Nam. Chính vì vậy, nước ta nhận lượng bức xạ lớn, ngày dài hơn đêm. Đây là thời điểm tốt nhất cho sự phát triển của cây lúa. Nếu đồng bào cấy muộn sau tháng 5 thì tiết trời chuyển sang thu, nhiệt độ hạ dần, ánh sáng kém làm lúa phát triển yếu, thỉnh thoảng có đợt gió mùa đông bắc nhiệt độ dưới 18 độ sẽ hạn chế lúa ra đòng, thụ phấn yếu, hạt lép dẫn tới năng suất kém.

Ngoài việc xác định mùa vụ, trong tục ngữ, người Tày còn đúc kết được kinh nghiệm chọn giống sao cho thích hợp với thời tiết: Găm buon pét slip hả/Rủng đây đăm co lả/Láp lá đăm co thua (Đêm 15 tháng 8/trăng sáng trong trồng giống lúa muộn/trăng sáng mờ mờ cấy giống lúa sớm). Đồng bào dân tộc Tày căn cứ vào ánh trăng rằm tháng 8 để chọn giống lúa, nếu trăng tròn vành vạnh, ánh sáng trong thì vụ tới cần chọn giống lúa muộn để cấy còn trăng chỉ sáng mờ mờ thì nên chọn giống lúa sớm để cấy.

Tục ngữ Tày không chỉ đúc rút kinh nghiệm trồng lúa mà còn đưa ra những kinh nghiêm trồng một số loại cấy khác: Bươn chiêng nẳm qua tặng/ Sli hả ván thúa ngà (Tháng giêng trồng dưa leo /Tháng tư, tháng năm gieo vừng đỗ) [3, tr. 192]. Cây vừng là loại cây nhiệt đới, ưa khí hậu nóng ẩm. Do vậy, mỗi vùng miền ở nước ta sẽ có thời điểm gieo trồng khác nhau. Theo quan niệm của đồng bào Tày, thời vụ thích hợp nhất để trồng là tháng 4 - tháng 5 .

Như vây, qua tục ngữ đồng bào dân tộc Tày đã đúc rút được nhiều kinh nghiệm về thời điểm gieo trồng hiệu quả. Nhưng kinh nghiệm ấy đã được thế hệ con em đồng bào thực hành trong sản xuất và góp phần mang lại cuộc sống no ấm cho người Tày.

\subsection{Trồng trọt}

Trong nông nghiệp kĩ thuật trồng trọt là yếu tố cốt lõi. Do vậy, kinh nghiệm về trồng trọt là một phần không thể thiếu trong tục ngữ Tày.

Đồng bào thường truyền nhau kinh nghiệm canh tác: rẩy óm chà, nà óm nặm (rẫy ủ cành, ruộng dầm nước), nghĩa là làm rẫy thì ủ cành lá cho mục, cho khô để đốt lấy tro làm phân bón cho cây trồng; còn làm ruộng thì ngâm nước cho đất ngấu. Khi làm đất đồng bào quan niệm: Thây nà lập đông, khẩu thuổm chang tổng, lậm cằn nuxa phura cằn tẩu (cày ruộng lập đông, lúa ngập đầy đồng, nặng trĩu đan nhau bờ trên bờ dưới)... Trong trồng trọt, đồng bào dân tộc Tày không 
chỉ chú trọng kĩ thuật làm đất mà họ còn rất quan tâm đến kĩ thuật trồng slíp co lả bấu tấng hả co hua (mười cây mạ cấy muộn không bằng năm cây mạ cấy sớm); Đăm nà tẳm ngoảng á, khẩu bấu quá ngài chiêng (Cấy ruộng tới lúc ve ran, gạo không qua cơm tết).

Phân bón đóng góp không nhỏ cho sự sinh trưởng của cây lúa, tập quán làm phân, ủ phân đã được đồng bào dân tộc Tày sử dụng thành thạo: Khủn lồng cằn nual Khẩu phura cằn tâư (Phân bón bờ trên/ Lúa ken bờ dưới) [3, tr.238]; Đăm chay lèo pỏn khil Khẩu bắp chắng đảy chình (Trồng, cấy phải bón phân / Ngô lúa mới bội phần) [3, tr. 211].

Đồng bào dân tộc Tày canh tác song hành ruộng nước và nương rẫy. Với mỗi loại hình canh tác đồng bào có kĩ thuật canh tác riêng: Hết rẩy ốm chà, hết nà ốm nặm (Làm nương phải dấm lá cây, làm ruộng phải ngâm nước) [3,tr. 226]; Lảy đảy buoon lé quà / Nà đảy buơn lả quát (Rẫy đày tháng làm cỏ/ Ruộng được tháng sục bùn) [3, tr 241]

Những kinh nghiệm về trồng trọt được đúc kết qua tục ngữ là nguồn tài liệu nông học quan trọng được đồng bào dân tộc Tày truyền từ đời này qua đời khác. Nó như kim chỉ nam cho hoạt động trồng trọt của đồng bào dân tộc Tày.

\subsection{Chăn nuôi}

Cũng giống như nhiều dân tộc khác, người Tày trong quá trình sinh sống ngoài tích lũy kinh nghiệm về hoạt động trồng trọt còn tích lũy được không ít kinh nghiệm chăn nuôi, săn bắn.

Để chăn nuôi đạt hiệu quả kinh tế cao thì việc lựa chọn vật nuôi đòi hỏi phải có kinh nghiệm từ khâu chọn giống đến chăm sóc. Trong khâu chọn giống, đồng bào chú trọng nhiều tới việc lựa chọn con cái: Vài mè lẻ xa tua toọng tòa (Trâu cái giống thì chọn con bụng to ) [3, tr. 107]; Xa lùa chiêm tái, dụ vài chiêm mé (Kén dâu xem bà mẹ, kén trâu giống xem con cái.) [3, tr. 109]; Mu mè chẻ xu lình (Nuôi lợn sề thiến như mộc nhĩ ngâm) [3, tr.92].

Chọn giống vật nuôi ngoài căn cứ vào đặc điểm giới tính thì đồng bào dân tộc Tày còn dựa vào các yếu tố về hình thức: Bấu dảo mò khẻo lài/ Bấu tạu wài khẻo phước (Không nuôi bò răng vằn/ Không tậu trâu răng đen.) [3, tr. 73]; Ma khúy xa tua ấc pháng (ngựa cưỡi cần tìm con rộng ngực) [3, tr. 89].

Trong tục ngữ Tày kinh nghiệm chọn giống vật nuôi được đồng bào tập trung phản ánh là chọn trâu, bò, ngựa, lợn... Điều này có lẽ bởi người Tày nói riêng và người Việt nói chung vốn là những cư dân nông nghiệp nên trong điều kiện sản xuất chưa phát triển thì trâu, bò là sức kéo không thể thay thế. Ngoài ra địa bàn cư trú của người Tày chủ yếu ở vùng núi, nơi có địa hình không bằng phẳng, nhiều dốc, phương tiện đi lại hiện đại còn hạn chế nên từ xa xưa đồng bào chủ yếu dùng sức người và sức ngựa. Do vậy, ngựa trở thành phương tiện giao thông nhanh, tiện lợi và phù hợp nhất. Lợn là vật nuôi để cung cấp thực phẩm cho bữa ăn hằng ngày, đồng thời cũng là con vật dùng để hiến tế trong các nghi lễ quan trọng.

\section{Kết luận}

Tri thức dân gian về lao động, sản xuất được phản ánh qua tục ngữ Tày là vốn kinh nghiệm vô cùng quý báu mà đồng bào muốn truyền dạy cho con cháu. Trong đó, đồng bào đã đưa ra những dự báo về thời tiết dựa trên thiên tượng, dự báo mùa vụ căn cứ vào các hiện tượng gần gũi như: quả chín, hoa nở, mùa lá, các tiết khí trong nông lịch. Để mùa vụ bội thu đồng bào truyền cho con cái những kinh nghiệm về làm đất, thời điểm và kĩ thuật canh tác. Trong chăn nuôi, đồng bào đã đúc rút kinh nghiệm chọn giống trâu, bò, ngựa, lợn... căn cứ trên các đặc điểm về giới tính và hình thức. Những tri thức dân gian này được đúc kết ngắn gọn, hàm súc và có giá trị lâu bền không chỉ trong sản xuất của người Tày mà có thể áp dụng rộng rãi.

\section{References}

1. Tran Thi An, Proverbs of Vietnamese Ethnic Minorities, Volume 1, Social Science Publishing House, 2013.

2. Tran Thi An, Proverbs of Vietnamese Ethnic Minorities, Volume 2, Social Science Publishing House, 2013.

3. Tran Thi An, Proverbs of Vietnamese Ethnic Minorities, Volume 3, Social Science Publishing House, 2013.

4. Trieu An, Hoang Quyet, Dictionary of idioms and proverbs of the Tay ethnic, National Cultural Publishing House, 1996.

5. Hoang Quyet, Hoang Trieu An, Idioms, proverbs, folk songs of Tay ethnic, Culture and Information Publishing House, 2014.

6. Do Huu Chau, Vietnamese Vocabulary Semantics, Education Publishing House, 1999.

7. Dinh Trong Lac, Nguyen Thai Hoa, Vietnamese Language Learning Style, Education Publishing House, 1996. 


\section{FOLK KNOWLEDGE IN PRODUCTION REFLECTED IN TAY ETHNIC'S PROVERBS}

\begin{tabular}{l}
\hline Article info \\
\hline Recieved: \\
15/7/2020 \\
Accepted: \\
20/9/2020 \\
\hline
\end{tabular}

Keywords:

folk, knowledge, prodution, labor, Tay

ethnic's proverbs.

\begin{abstract}
Surveying folk knowledge in order to introduce, preserve and promote valuable experiences of the Tay ethnic is an urgent need. Because the language and culture of the ethnic minorities in general and Tay ethnic in particular are facing that global risk of lost gradually and perish. Surveying folk knowledge about labor and production in Tay ethnic's proverbs, through published publications shows that people often pay attention to experiences in weather forecasting, seasons, cultivation, and breeding... These folk knowledge should be selected to teach children of the Tay ethnic in particular and the community in general.
\end{abstract}

